\title{
LA PRODUCCIÓN ECOLÓGICA DE CÍTRICOS COMO ESTRATEGIA DE COMPETITIVIDAD EN LOS MERCADOS SATURADOS. ESTRUCTURA PRODUCTIVA DE LAS EXPLOTACIONES EN ANDALUCÍA
}

\author{
Remedios Larrubia Vargas \\ Juan José Natera Rivas \\ Susana Rosa Navarro Rodríguez \\ Departamento de Geografía. Universidad de Málaga. \\ rlarrubia@uma.es, jnatera@uma.es, susanros@uma.es
}

\section{RESUMEN}

En el contexto actual de crisis de la citricultura, la posibilidad de diferenciación de la producción mediante la agricultura ecológica es una opción que los productores tienen para mejorar las cuentas de sus explotaciones y así se pone de manifiesto en los numerosos estudios existentes. Sin embargo, en estos estudios ha quedado marginado el análisis de las estructuras de estas explotaciones, fundamental desde el momento en que su inadecuada estructura es uno de los principales problemas del sector citrícola. Nuestro objetivo es comprobar si existen diferencias estructurales entre el sistema de cultivo ecológico y el convencional que puedan incidir en el funcionamiento de las explotaciones. Para ello hemos utilizado la información obtenida de los Microdatos del último Censo Agrario (2009). El aplicar a esta información dos instrumentos de análisis estadístico (análisis factorial y análisis de conglomerados) nos ha permitido realizar una clasificación de ambos tipos de explotaciones, que debe interpretarse como una síntesis de sus características estructurales.

Palabras clave: cítricos ecológicos, dimensión económica, diferenciación de la producción.

Fecha de recepción: julio 2014.

Fecha de aceptación: abril 2015. 


\section{ABSTRACT}

The possibility of production differentiation through organic agriculture is an option that farmers have in order to improve the economic results of their orchards, as much research has shown. Anyway, the analysis of structural characteristics of this orchards, has not been studied with the same depth, although one of the main problems of the citric sector is it's inadequate structure. In this context, our aim is search for structural differences between both systems of production (organic and conventional). We have used 2.009 agrarian census microdata, and we have applied multivariate analysis tools, and using them, we have been able to build a classification of both of organic and conventional orchards, that must be interpretated as a synthesis of their structural characteristics.

Keywords: organic citric, economic dimension, production differentiation.

En la actualidad el cultivo de los cítricos en España y Andalucía tiene problemas estructurales muy serios: el paulatino envejecimiento de los agricultores y su desprofesionalización, la creciente dependencia de empresas foráneas para la comercialización, la entrada de empresas productoras con mejor equipación tecnológica en un mercado de excedentes, la competencia cada vez más intensa de otros países y el reducido tamaño de las explotaciones. Problemas que condicionan la viabilidad y productividad de los cultivos porque dificultan o impiden la modernización de las explotaciones.

En este contexto de crisis de la citricultura, la posibilidad de diferenciación de la producción es una de las escasas opciones que los productores tienen a la hora de lograr un incremento de los precios obtenidos por sus producciones, mejorando las cuentas de la explotación.Una diferenciación que si bien podría conseguirse mediante distintas opciones, como cumplimiento de protocolos de buenas prácticas agrícolas -GAP-, Producción Integrada o Denominación de Origen, entre otras, en el caso de los citricultores andaluces es la agricultura ecológica (AE, en adelante) la que, hasta el momento, ha sido la opción más extendida, como alternativa real para mejorar los resultados económicos de las explotaciones.

Desde que la AE irrumpe con fuerza han sido abundante los estudios y análisis donde se comparan distintos aspectos de los sistemas de cultivos ecológicos frente a los tradicionales; desde las formas y manejos de explotaciones, las técnicas de laboreo, pasando por los precios de los productos, los costes de producción y, por consiguiente, la rentabilidad de las explotaciones en ambos sistemas. Respecto a este último aspecto la conclusión que más se repite en el análisis bibliográfico es que no existen grandes diferencias entre ambos sistemas de cultivo, aunque se destacan dos aspectos; por un lado, que los rendimientos bajan ligeramente, los costes de producción aumentan, pero los precios algo más altos de los productos son el desencadenante del balance económico más favorable en los sistemas ecológicos y, por otro lado, la posibilidad de encontrar un nicho de mercado donde asegurar la venta de la cosecha, que ha supuesto también cambios en los circuitos de comercialización (Navarro, 2002; Alonso, 2008; Julía, 2004; Domínguez, 2006; Porcuna, 2010, Junta de Andalucía, 2011).

Un aspecto que ha quedado al margen en los profusos estudios existentes y que podía complementar los anteriores aspectos es el análisis comparativo de las estructuras de las explotaciones en ambos sistemas de cultivo. En este punto, nos preguntamos si también 
desde el punto de vista estructural se aprecian cambios evidentes entre las explotaciones citrícolas convencionales y ecológicas que puedan incidir en su rentabilidad. Este es, pues, el objetivo de la presente investigación, en la que como punto de partida establecemos el estado de la cuestión de la AE como marco conceptual de referencia.

\section{LAAGRICULTURA ECOLÓGICA}

\section{I.1. Concepto, aplicación y regulación}

Todos conocemos que la agricultura modifica las relaciones entre los seres vivos y permite la obtención de recursos. Pero desde finales del s. XVIII y principios del s.XIX la aplicación de nuevas técnicas de producción con la finalidad de incrementar al máximo los rendimientos por unidad de superficie, ha generado importantes externalidades negativas en ocasiones irreversibles (erosión, contaminación y efectos perniciosos sobre la salud humana, etc.). Por otro lado, los problemas crónicos de financiación de la UE, junto al incremento de los costes y en paralelo de excedentes agrarios, entre otros motivos, han forzado al estudio de modelos que limiten la superproducción y los costes de ayuda a la agricultura, sin olvidar las exigencias, cada día mayores, de calidad y seguridad alimentaria por parte de los consumidores.

Para adaptarse a este nuevo escenario se ha puesto en funcionamiento una serie de métodos agrícolas que aproximan la agronomía a la ecología, a los que en conjunto se conoce con el nombre de «Agricultura Sustentable o Sostenible» (Programa 21 de la Conferencia de Río de Janeiro de 1992, e Informe Brundtland elaborado en 1.987 por la Comisión Mundial para el Medio ambiente y el Desarrollo (Cadenas, 1995)). Esta denominación de «agricultura sostenible» es el último eslabón de una cadena conceptual que gira en torno a la práctica de una agricultura alternativa a la intensiva, que ha ido acompañada de un amplio espectro de adjetivos diferentes a lo largo del tiempo (ecológica, biológica, orgánica, biodinámica, etc.)

A nivel oficial, la legislación comunitaria (Decreto CEE 2.092/91) ${ }^{1}$ daba la opción de aplicar en cada uno de los Estados Miembros uno de los términos, habiendo elegido la legislación española (Orden 4-10-89) el calificativo de «AE», que además es uno de los más frecuentemente seleccionados por el resto de Estados de la UE.

La UE entiende por AE «un sistema agrario cuyo objetivo fundamental es la obtención de alimentos de la máxima calidad, respetando el medio ambiente y conservando la fertilidad de la tierra, mediante la utilización óptima de los recursos naturales y sin el empleo de productos químicos de síntesis, procurando así un desarrollo agrario perdurable» (Labrador, 1991; Labrador et al, 1999).

En líneas generales, los métodos empleados en la AE no son algo nuevo, puesto que la no utilización de fertilizantes químicos, el control manual de las malas hierbas o combatir las plagas con otras especies, era la norma en la agricultura tradicional. Pero frente a aquella, la nueva agricultura alternativa posee dos aspectos diferenciadores, la incorporación de las innovaciones técnicas y en ocasiones una componente ideológica en los hombres que la practican, que intentan obtener unos productos de calidad, conscientes de conseguirlo mediante

$1 \quad$ DO L 198 de 22-7-1991. 
unas prácticas que no deterioran el medio ambiente a lo que también hay que sumar la garantía de conseguir unos resultados económicos que permitan la reproducción de las explotaciones (Larrubia, 1998). En este sentido es destacable la definición dada por la Sociedad para la Conservación del Suelo y el Agua de los EEUU (Duesterhaus, 1990), por hacer explícito uno de los requerimientos sustanciales de la $\mathrm{AE}$ en la actualidad, la necesidad de ser rentable para el que la cultiva, aspecto que también se explicita en el concepto de AE de la Federación Internacional de Movimientos de AE (IFOAM).

Para dar cumplimiento a los objetivos de la AE era necesario codificar las prácticas y todo el proceso ecológico, crear un cuerpo legislativo capaz de protegerla y de garantizar a los consumidores la calidad de lo que demandan como ecológico, asegurando la transparencia en todas las fases del proceso productor-comercializador.

En España los primeros pasos de este proceso arrancan en 1988, con dos Reales Decretos sobre productos agrícolas obtenidos sin el empleo de productos químicos ${ }^{2}$. Posteriormente en 1989 se aprobó el Reglamento de la Denominación Genérica «AE y su Consejo Regulador» ${ }^{3}$ que fue de aplicación hasta la entrada en vigor del Reglamento europeo (CEE) 2.092/914 sobre la producción agrícola ecológica y su indicación en los productos agrarios y alimenticios (Comisión Europea-COAG, 2006). Este reglamento supuso el reconocimiento legal de la $\mathrm{AE}$ en el marco de la UE y perseguía homogenizar la normativa existente a escala nacional, con el fin de lograr una mayor transparencia en el mercado comunitario y aumentar la confianza de los consumidores

Para garantizar el cumplimiento de la normativa de producción ecológica, el Reglamento (CE) n ${ }^{\circ} 834 / 2007$ prevé dos sistemas de control, de forma que éste se ejerza, bien por autoridades de control públicas o bien por organismos privados autorizados y supervisados por la autoridad competente. En España, hasta el momento, se ha optado por el sistema de autoridades de control públicas, a través de Consejos o Comités de AE territoriales, y así en Andalucía desempeña este papel el Comité Andaluz de AE, órgano descentralizado y consultivo de la Consejería de Agricultura y Pesca, al que fueron encomendadas las labores de certificación y control establecidas en el Reglamento (CEE) n ${ }^{\circ}$ 2.092/91.

En el marco del Reglamento $(\mathrm{CE}) \mathrm{n}^{\circ} 2.078 / 92$ sobre métodos de producción agraria compatibles con las exigencias de protección del medio natural, la Administración Nacional dispuso un sistema de ayudas a la producción ecológica que supuso el respaldo definitivo a la expansión de este sector ${ }^{5}$. Una política de protección que la Agenda 2.000 ha

2 - R. D 728/88 de 8 de junio (BOE $\mathrm{n}^{\circ} 166$ de 12 de julio de 1988).

- R.D. 759/88 de 15 de julio de 1988 (BOE nº 174 de julio de 1988).

3 Orden 4 de octubre de 1989, BOE, 5 de octubre de 1989.

4 DO L198 de 22-7-91.

5 A partir de la década de los 90, la UE establece un régimen de ayudas para la AE cofinanciadas por la Sección Garantía del Feoga y los Estados Miembros. Dichas ayudas se desarrollan y se aplican en nuestro país a partir del Real Decreto 51/1995 de 20 de enero y la orden de 28 de junio de 1995 de la Consejería de Agricultura y Ganadería que desarrolla el reglamento anterior en función del cultivo y en Andalucía a través de la orden de 1 de diciembre de 1995 (Boja n ${ }^{\circ} 16321$ de diciembre de 1995). En el caso de los cítricos, que es el cultivo que nos ocupa, según la Orden de 20 de noviembre de 2007 dicha ayuda es de 510,4€ por hectárea. Esta ayuda es compatible con otras de carácter general o particular para estos productos, excepto aquellas que se engloban dentro de las medidas agroambientales y sean incompatibles entre sí. El compromiso que se adquiere es que las fincas que reciben ayudas se mantengan en producción ecológica certificada al menos 5 años. 
reforzado, manteniendo las citadas ayudas a la producción ecológica dentro de las medidas «agroambientales», que se recogen en el Reglamento (CE) n 1257/99 que unifica todas las ayudas al desarrollo rural (Rodríguez, 2002); política de protección medioambiental que se ha mantenido con ligeras matizaciones en la reforma de la PAC de 2003 y se ha acentuado en la última reforma (2015-2020).

El importe de las ayudas a la AE está en función del tipo de cultivo, del período de tiempo que se lleve cultivando y del grado de dedicación a la actividad. En la actualidad todas la CCAA han publicado normativas en las que regulan la concesión de subvenciones para la ayuda y fomento de la AE. Andalucía desde el año 2002 ha estado apoyando activamente el sector productor a través de los denominados «Planes Andaluces de AE» (PAAE). El primer plan cubre el período 2002-2006 y el segundo se desarrolla entre 2007 y 2013. A través de estos planes se apoya a la AE mediante ayudas agroambientales, transformación y comercialización, desarrollo de estrategias para ciertos sectores (hortofruticultura y avicultura), protección y transparencia de la producción ecológica, etc (Junta de Andalucía 2002-2006; 2007-2013). En la actualidad, y al hilo de la última Reforma de la PAC, el Gobierno andaluz está elaborando el III PAAE (2014-2020). El Plan debe consolidar el sector y ser una herramienta para afrontar los desafíos de la sostenibilidad, la seguridad alimentaria, el desarrollo rural y el cambio climático en Andalucía.

\section{I.2. Desarrollo y evolución de la agricultura ecológica}

A nivel mundial, este tipo de agricultura se caracteriza por una tendencia alcista, ya alcanza a 160 países y existen 37,2 millones de Ha certificadas (0,9\% SAU mundial), reuniendo en 2009 tan sólo ocho países el 70\% de dicha superficie: Australia (1/3 del total) seguida de Argentina, China, Estados Unidos, Brasil, España, India, Italia, Uruguay y Alemania (Porcuna, 2010). Alrededor de dos terceras partes de esta superficie son pastos (23 millones de Ha) y 5,5 millones de Ha tierras agrícolas (15\% del total). La mayor parte de la superficie ecológica dedicada a cultivos corresponde a cereales (2,5 millones de $\mathrm{Ha})$, seguidos de los forrajes (1,8 millones) y las hortalizas ( 0,22 millones $)$, mientras que los cultivos permanentes en conjunto suman 2,4 millones de Ha.

En cuanto a los mercados mundiales, el valor de las ventas internacionales fue de 50,9 millones de dólares en 2008, localizándose especialmente dicha demanda en el norte de América y en Europa. Sobre sus perspectivas de crecimiento «Organic Monitor» ${ }^{6}$ revela que las tendencias a corto y medio plazo de los mercados ecológicos se definirán por un exceso de producción, estabilización de los precios, consolidación de la industria y aumento de la sofisticación de la demanda.

Los puntos fuertes que presenta la $\mathrm{AE}$ se deben sobre todo a la imagen de calidad y salubridad que se tiene de estos productos, pero la falta de recursos humanos, técnicos y económicos de los productores, el desconocimiento por parte del consumidor y la falta de formación específica en AE para el asesoramiento a productores o experimentación científica, son algunos de los puntos débiles que presenta el buen desarrollo de la AE. A lo que hay que añadir la complejidad de las normativas, los largos periodos de reconversión y tramitación y la insuficiente inversión;

6 «Organic Monitor» es una consultoría especializada que se centra en la investigación de productos sostenibles. 
sin olvidar que existe un bajo nivel de consumo de este tipo de productos debido a una estructura de comercialización limitada y un surtido de productos escasos y excesivamente caros.

\section{I.2.1. Situación y evolución en España y en Andalucía.}

La AE española se caracteriza actualmente por su diversidad, fruto de los diferentes ámbitos agrarios, sistemas de producción, climas y culturas existentes, si bien su desarrollo ha sido posterior al de las principales regiones europeas. Donde primero arraigó la AE fue en Cataluña, durante los años 70, por influencia del movimiento de AE francés, y a partir de entonces con el apoyo de distintas asociaciones, organizaciones y revistas (Asociación Vida Sana, Asociación de Agricultura Biodinámica de España, Revista Integral, etc.) se promueven y difunden los logros y ventajas del nuevo método al resto del territorio español (Ruiz Moya, 1994).

En estos momentos iniciales y durante la mayor parte de la década de los 80 , la mayoría de los agricultores ecológicos practicaban esta actividad por afición, por honradez a sus principios, siendo el destino prioritario de la producción el autoconsumo, teniendo como hándicap la mala calidad externa del producto, frente a la excelente presentación y presencia de los productos provenientes de la agricultura convencional. En este sentido hay que señalar que la evolución de la AE no sólo ha sido en extensión superficial sino también cualitativa, puesto que en la actualidad, tanto su aspecto externo, como su presentación están en la misma línea que la que presentan los productos convencionales.

El cuadro 1 nos permite apreciar que el aumento de la superficie ecológica en España y Andalucía ha sido rápido y concentrado en un corto período de tiempo, con dos momentos claves: el año 1996, cuando se produce el sorprendente salto cuantitativo de la AE, gracias al incentivo de la subvención comunitaria y el año 2008, en el que se produjo un incremento del $25 \%$ respecto a la campaña anterior. Ello ha determinado que en la actualidad España se haya convertido en el país de la UE-27 que más superficie de cultivo dedica a producción ecológica.

En el año 2012 Andalucía lidera el ranking español de superficie ecológica, aportando el $54 \%$ del total, con casi un millón de Ha, a distancia, con unas 250.000 Ha, se sitúa CastillaLa Mancha $(16,91 \%)$ y tras ellas y con más de 50.000 Ha cada una aparecen Cataluña, Extremadura, Navarra, Aragón y Murcia.

Los cultivos hacia los que se ha orientado la $\mathrm{AE}$ son bosques, prados y praderas que representan a nivel nacional el 57,51\% de la superficie ecológica, aportando Andalucía a este aprovechamiento extensivo el 74,17\%, seguida a mucha distancia de las comunidades de Cataluña, Castilla-La Mancha y Extremadura. Además esta categoría supone el 78,95\% de la superficie ecológica andaluza. Los siguientes aprovechamientos en cuanto a importancia superficial en esta práctica son los cereales y legumbres, el olivar y los frutos secos, tanto a nivel estatal como regional, significando en conjunto el 27,64\% de la superficie ecológica estatal y el $15,72 \%$ de la andaluza (Cuadro 2 ).

Frente a estos cultivos, hay que destacar un conjunto de productos de menor extensión (menos del 0,5\% de la superficie ecológica tanto nacional como andaluza), pero «fundamentales por su dimensión económica», que son frutales, cítricos, hortalizas y tubérculos. Estos cultivos tienen gran importancia de modo general por su aportación a la producción final agrícola, debido a su matiz exportador, y, de modo especial, para Andalucía, por la alta contribución que realiza a la superficie ecológica dedicada a estos cultivos en España $(63,12 \%)$. 


\begin{tabular}{|c|c|c|c|c|}
\hline \multirow{2}{*}{ AÑOS } & \multicolumn{2}{|c|}{ ESPAÑNA } & \multicolumn{2}{|c|}{ ANDALUCÍA } \\
\hline & Superficie (Ha) & $\mathbf{N}^{\mathbf{o}}$ productores & Superficie (Ha) & $\mathrm{N}^{\mathbf{0}}$ productores \\
\hline 1991 & 4.235 & 346 & 2.200 & --- \\
\hline 1994 & 17.208 & 1.042 & 3.987 & 237 \\
\hline 1996 & 103.735 & 3.526 & 20.722 & 837 \\
\hline 1998 & 269.465 & 7.392 & 47.470 & 1.769 \\
\hline 2000 & 380.838 & 13.394 & 69.041 & 2.749 \\
\hline 2002 & 665.055 & 16.521 & 225.598 & 4.024 \\
\hline 2004 & 733.181 & 16.013 & 326.472 & 5.195 \\
\hline 2006 & 926.390 & 17.204 & 537.269 & 6.195 \\
\hline 2008 & 1.317 .752 & 21.291 & 784.067 & 7.777 \\
\hline 2010 & 1.674 .119 & 27.877 & 903.111 & 9.923 \\
\hline 2012 & 1.756 .548 & 30.462 & 949.025 & 9.747 \\
\hline
\end{tabular}

Fuente: Estadísticas de AE. MMARM. Varios años. Elaboración propia.

Cuadro 2

SUPERFICIE DE AGRICULTURA ECOLÓGICA POR MASAS DE CULTIVO EN ESPAÑA YANDALUCÍA EN 2012

\begin{tabular}{|l|r|r|r|r|r|}
\hline \multicolumn{1}{|c|}{ CULTIVOS } & \multicolumn{1}{c|}{$\begin{array}{c}\text { España } \\
\text { (Ha) }\end{array}$} & \multicolumn{1}{c|}{$\%$} & $\begin{array}{c}\text { Andalucía } \\
\text { (Ha) }\end{array}$ & \multicolumn{1}{c|}{$\%$} & $\begin{array}{c}\text { \% Andalucía/ } \\
\text { España }\end{array}$ \\
\hline Cereales y legumbres & 219.199 & 12,48 & 56.538 & 5,96 & 25,79 \\
\hline Frutales subtropicales & 1.969 & 0,11 & 958 & 0,1 & 48,65 \\
\hline Cítricos & 6.275 & 0,36 & 3.961 & 0,42 & 63,12 \\
\hline Frutos secos & 98.272 & 5,59 & 37.843 & 3,99 & 38,51 \\
\hline Otros frutales & 5.461 & 0,31 & 1.348 & 0,14 & 24,68 \\
\hline Hortalizas y tubérculos & 10.365 & 0,59 & 6.195 & 0,65 & 59,77 \\
\hline Vid & 81.262 & 4,62 & 757 & 0,08 & 0,93 \\
\hline Olivar & 168.039 & 9,57 & 54.800 & 5,77 & 32,61 \\
\hline Prados, praderas y bosque & 1.010 .238 & 57,51 & 749.327 & 78,96 & 74,17 \\
\hline Otros & 155.497 & 8,85 & 37.298 & 3,93 & 23,99 \\
\hline Total & 1.756 .547 & 100 & 949.025 & 100 & 54,03 \\
\hline
\end{tabular}

Fuente: Estadísticas de AE. MMARM. (2013). Elaboración propia.

La AE en 2005 generó en Andalucía una producción final agrícola estimada en 123,1 millones de euros siendo los hortícolas, con un 34,5\% de dicha producción, el sector de mayor relevancia económica, tras los que encontramos al olivar, los cítricos y los subtropicales con un $30,8 \%, 12,2 \%$ y $7,6 \%$, respectivamente. En total estos cuatro grupos de cultivos representan el 84,9\% de la producción final de la AE (Junta de Andalucía, 2007-2013). Al comparar estos resultados con sus equivalentes convencionales, el cálculo realizado 
estima en un $72 \%$ mayor la producción final ecológica en el caso de hortícolas y de forma extraordinaria supone un $200 \%$ superior la PFA en los ecológicos en el caso de los cítricos.

En la distribución provincial de la superficie ecológica Málaga y Almería aparecen como las provincias que menos superficie ecológica incorporan al total andaluz, respectivamente un 3,5 y un 4,2\% (menos de 35.000 Ha cada una), mientras que el resto de provincias cuentan con más de 100.000 Ha, situándose en primera posición Cádiz, Huelva y Jaén con más de 150.000 Ha cada una y aportan el 56\% de la superficie ecológica regional. La tónica del desarrollo de la AE ha sido la especialización productiva en las diferentes provincias y comarcas en relación a la orientación productiva que cada una de ellas tiene en producción convencional. Así destacan los frutos secos en Almería y Granada, el olivar en Córdoba, Sevilla y Jaén, los hortofrutícolas en Almería y Málaga y los cultivos extensivos en Granada y Córdoba (Cuadro 3).

Cuadro 3

SUPERFICIE DE AGRICULTURA ECOLÓGICA POR TIPOS DE CULTIVOS EN ANDALUCÍA EN 2012 (HA)

\begin{tabular}{|l|r|r|r|r|r|r|r|r|r|}
\hline \multicolumn{1}{|c|}{ Cultivos } & Almería & Cádiz & Córdoba & Granada & Huelva & Jaén & Málaga & Sevilla & Total \\
\hline $\begin{array}{l}\text { Cereales y } \\
\text { Legumbres }\end{array}$ & 6.114 & 11.589 & 8.837 & 21.190 & 1.142 & 1.256 & 875 & 5.532 & 56.538 \\
\hline $\begin{array}{l}\text { Hortalizas y } \\
\text { tubérculos }\end{array}$ & 1.904 & 491 & 614 & 2.060 & 227 & 57 & 294 & 544 & 6.195 \\
\hline Cítricos & 1.190 & 206 & 165 & 24 & 621 & -- & 1.229 & 523 & 3.961 \\
\hline $\begin{array}{l}\text { Frutales } \\
\text { subtropicales }\end{array}$ & 1 & 60 & 0,01 & 174 & 87 & 0,2 & 634 & 0,1 & 958 \\
\hline Olivar & 1198 & 2.720 & 21.847 & 4.255 & 4.210 & 5.645 & 2.596 & 12.235 & 54.800 \\
\hline Vid & 250 & 72 & 64 & 251 & 15 & 5 & 93 & 3 & 757 \\
\hline Frutos secos & 15.456 & 56 & 219 & 18.941 & 1.210 & 277 & 1.579 & 102 & 37.843 \\
\hline Otros frutales & 83 & 24 & 47 & 152 & 302 & 353 & 322 & 61 & 1.348 \\
\hline $\begin{array}{l}\text { Prados, praderas, } \\
\text { bosques }\end{array}$ & 8.567 & 164.796 & 71.822 & 52.961 & 171.733 & 157.986 & 25.194 & 96.264 & 749.327 \\
\hline Otros & 5.275 & 1.672 & 10.056 & 13.040 & 700 & 767 & 348 & 1.862 & 33.723 \\
\hline Total & 40.180 & 183.379 & 114.143 & 113.478 & 180.345 & 166.396 & 33.331 & 117.767 & 949.025 \\
\hline
\end{tabular}

Fuente: Estadísticas de AE. MMARM. (2013). Elaboración propia.

\section{I.2.2. El cultivo ecológico de los cítricos}

Según datos de la FAO, el mercado mundial de cítricos se encuentra en expansión. Su producción se ha duplicado en las tres últimas décadas, pasando de 47 a 122 millones de TM en 2008, haciéndose extensiva esta progresión al territorio español con 6 millones de toneladas (2009), con la mandarina como grupo varietal de mayor producción (Spreen T., 2010). Los cítricos constituyen el principal grupo de frutales cultivado en España, exactamente el 60,9\% de la superficie cultivada de frutales corresponde a cítricos, siendo la Comunidad Valenciana la que ocupa la primera posición $(56,7 \%)$ en el ranking de zonas productoras, seguida por la Comunidad Andaluza (24,9\%) y la Murciana (13,5\%) (Junta de Andalucía, 2011). 
Si bien la superficie citrícola española se ha incrementado de forma sostenida en las últimas décadas, durante este periodo se ha producido una reducción de la superficie cultivada en la C. Valenciana sobre el total nacional, prácticamente coincidente con el incremento experimentado por la superficie en Andalucía. Aunque en esta comunidad, todos los grupos de cultivo han crecido a un ritmo muy superior al del resto del territorio español, cabe destacar cómo los cítricos han duplicado la escasa superficie con que contaban a principios de la década del 2000.

Aunque la superficie de cítricos ecológicos no es destacable en volumen dentro del cómputo total de superficie ecológica ( $0,35 \%$ en España y 0,41\% en Andalucía), sin embargo ya hemos señalado que ésta sí tiene gran valor estratégico al igual que la destinada a otros productos de regadío como frutales y hortalizas por su mayor contribución a la producción final agraria y como alternativa de calidad en un mercado saturado de cítricos convencionales. Por ello, un aspecto que puede condicionar poderosamente en los próximos años la revalorización de los cultivos de cítricos es la dedicación a la producción ecológica, como una respuesta al incremento continuo de las exigencias de salubridad y calidad de los alimentos, tanto por parte de los consumidores como de las administraciones, y de protección del medio ambiente.

A nivel nacional, España ocupaba en 2010 el tercer puesto en el mercado mundial de cítricos ecológicos, con la naranja a la cabeza de la producción tras Italia y Grecia. Pero Andalucía aporta el 63,12\% de la superficie citrícola ecológica española, habiéndose multiplicado por cuatro durante la última década dicha superficie. La producción de cítricos ecológicos en Andalucía, por tanto, se sitúa por encima de las principales comunidades autónomas que destacan en la producción de cítricos convencionales (Comunidades valenciana y murciana). Localizándose el área principal de producción de cítricos ecológicos en las provincias de Málaga $(31,02 \%)$ y Almería $(30,06 \%)$, a las que siguen Huelva $(15,68 \%)$ y Sevilla $(13,22 \%)$ (Cuadro 4).

Cuadro 4

EVOLUCIÓN DE LA SUPERFICIE DE CIITRICOS ECOLÓGICOS EN ANDALUCÍA

\begin{tabular}{|l|r|r|r|r|r|r|}
\hline \multirow{2}{*}{ PROVINCIAS } & \multicolumn{2}{|c|}{2001} & \multicolumn{2}{c|}{$\mathbf{2 0 0 6}$} & \multicolumn{2}{c|}{$\mathbf{2 0 1 2}$} \\
\cline { 2 - 7 } & Ha & $\mathbf{\%}(\mathbf{1})$ & Ha & \%(1) & Ha & \multicolumn{1}{c|}{ (1) } \\
\hline Almería & 235 & 3,4 & 537 & 7,01 & 1.190 & 13,58 \\
\hline Cádiz & 6 & 0,34 & 8 & 0,44 & 206 & 7,29 \\
\hline Córdoba & 1 & 0,02 & 2 & 0,03 & 165 & 1,44 \\
\hline Granada & 2 & 0,34 & 9 & 1,5 & 24 & 2,34 \\
\hline Huelva & 13 & 0,14 & 232 & 2,3 & 621 & 0,11 \\
\hline Jaén & --- & -- & -- & -- & -- & -- \\
\hline Málaga & 219 & 4,1 & 393 & 6,9 & 1.229 & 10,77 \\
\hline Sevilla & 139 & 2,61 & 216 & 1,3 & 523 & 1,78 \\
\hline Total & 617 & 1,46 & 1.400 & 2,9 & 3.961 & 4,65 \\
\hline
\end{tabular}

(1) Porcentaje respecto al total de cítricos en cada provincia.

Fuente: Estadísticas de AE. MMARM. Varios años. Elaboración propia. 


\section{LA ESTRUCTURA PRODUCTIVA DE LA EXPLOTACIONES DE CÍTRICOS ECOLÓGICOS EN ANDALUCÍA}

\section{II.1. Las explotaciones de cítricos en el Censo Agrario. Selección y metodología}

En los apartados anteriores hemos querido contextualizar la AE, prestando atención a la importancia tanto superficial como económica de los cítricos en el territorio andaluz, así como también a la concentración espacial de su producción. No obstante, y dado que nuestro objetivo esencial es analizar la estructura productiva de las explotaciones de cítricos ecológicos y su comparación con la de los convencionales, es necesario, hacer algunas precisiones con respecto a la fuente y a los métodos empleados. La información que vamos a utilizar proviene de los Microdatos del Censo Agrario más reciente (2009), que, como es sabido, están referidos a cada una de las explotaciones agrarias censadas en España, lo que permite una caracterización muy acabada de cada una de ellas, tanto como lo permiten las preguntas del cuestionario censal. En nuestro caso, y como inmediatamente veremos utilizando esta información tan detallada hemos procedido a caracterizar y comparar los dos tipos de explotación de cítricos, a partir de su tamaño -tanto superficial como económico- y del trabajo que demandan. Pero además hemos ido un paso más allá, al construir una clasificación de ambos tipos de explotación, que debe interpretarse como una síntesis de sus características estructurales. Gracias a que contamos con la información referida a cada explotación individual, hemos podido emplear dos instrumentos estadísticos de síntesis en su construcción: por un lado, un análisis factorial de componentes principales, a través del que hemos identificado un reducido número de dimensiones que subyacen en el conjunto de características individuales de las explotaciones seleccionadas. Por otro lado, un análisis de conglomerados, alimentado con los resultados anteriores, que nos ha permitido agrupar las explotaciones en grupos caracterizados porque la varianza intragrupos está minimizada, y maximizada la varianza intergrupos. El resultado es una síntesis de toda la información obtenida de los microdatos, a partir de la cual podemos no sólo caracterizar los grupos de explotaciones de cítricos que pueden encontrarse en Andalucía, sino también comparar los correspondientes a las convencionales con las ecológicas.

El Censo Agrario de 2009 nos informa que en Andalucía existían 70.458,26 Ha de cítricos, distribuidas en 11.895 explotaciones, y en cuanto a la superficie de cítricos ecológicos, en dicha fuente aparecen recogidas un total de 2.592,02 Ha, apenas un 3,67\% del total de cítricos, distribuidas en 647 explotaciones.

Sin embargo, es necesario indicar que en un número determinado de explotaciones, los cítricos, pese a estar presentes en su SAU, se resuelven como un aprovechamiento marginal, minoritario en el mejor de los casos, ya sea desde el punto de vista de lo que significan sobre la superficie, o sobre la producción de la explotación. Por ello en nuestro análisis creemos pertinente no considerar todas las explotaciones en las que hay presencia de cítricos en su SAU, sino tan sólo aquellas que hemos venido a denominar «explotaciones citrícolas», y que identificamos como aquellas definidas por la OTE (Orientación Técnico Económica, en función de la producción estándar) 362=cítricos, más las explotaciones en las que el porcentaje de la superficie de cítricos es de al menos el $50 \%$ de la SAU total. 
Una vez realizada esta primera selección, hemos procedido a dividirlas en dos grupos. El primero, compuesto por las explotaciones en las que no está presente el cultivo ecológico de cítricos, que hemos denominado «explotaciones citrícolas convencionales», un total de 6.997 que ocupan $56.320 \mathrm{Ha}$. Y un segundo grupo, en el que el cultivo de cítricos ecológicos sí está presente, un total de 426 explotaciones entre las que se distribuyen 1.481,12 Ha de este tipo de cultivo.

En el cuadro 5, donde se representa la selección realizada, observamos que en el cultivo tradicional se mantiene el ranking provincial que apreciamos atendiendo a la superficie censal: Sevilla, Huelva y Córdoba, reúnen el 77,28\% del total. Sin embargo en el cultivo ecológico, Huelva es reducida a la cuarta posición, y tras Almería encontramos a Málaga y Sevilla, que en conjunto ya suponen el $85,25 \%$ de la extensión de este aprovechamiento, lo que parece indicativo de que el cultivo en la provincia onubense en un gran porcentaje de explotaciones presentaba un carácter no fundamental.

Cuadro 5

«EXPLOTACIONES CITRÍCOLAS» SELECCIONADAS

\begin{tabular}{|c|c|c|c|c|c|c|}
\hline & \multicolumn{3}{|c|}{ Convencional } & \multicolumn{3}{|c|}{ Ecológico } \\
\hline & SAU & $\begin{array}{c}\text { Ha de } \\
\text { cítricos }\end{array}$ & Explotaciones & SAU & $\begin{array}{l}\text { Ha de } \\
\text { cítricos }\end{array}$ & Explotaciones \\
\hline Almería & $6.692,49$ & $4.388,58$ & 1.141 & 916,08 & 763,96 & 268 \\
\hline Cádiz & $3.900,03$ & $1.756,09$ & 248 & 8,02 & 6,42 & 4 \\
\hline Córdoba & $18.749,16$ & $9.428,64$ & 664 & 8,42 & 8,42 & 3 \\
\hline Granada & $1.391,49$ & 549,07 & 566 & 12,27 & 9,28 & 9 \\
\hline Huelva & $18.844,01$ & $13.011,25$ & 479 & 220,14 & 194,34 & 8 \\
\hline Jaén & 173,42 & 106,55 & 21 & 0 & 0 & 0 \\
\hline Málaga & $9.920,33$ & $5.991,55$ & 2.292 & 368,82 & 288,37 & 98 \\
\hline Sevilla & $35.988,37$ & $21.088,42$ & 1.586 & 241,35 & 210,33 & 36 \\
\hline Andalucía & $95.659,3$ & $56.320,15$ & 6.997 & $1.775,10$ & $1.481,12$ & 426 \\
\hline
\end{tabular}

Fuente: Microdatos del Censo Agrario (2009). Elaboración propia.

A continuación vamos a realizar una comparación estructural entre las explotaciones convencionales y ecológicas de cítricos que hemos definido como no marginales, a partir de la información suministrada por el Censo Agrario de 2009. Para ello apuntaremos información sobre su tamaño, personalidad jurídica y dimensión económica, para finalizar con una clasificación de aquellas cuyo titular es persona física, que son las mayoritarias en todos los intervalos de extensión generados (por encima del 60\%), a excepción de las superiores a 50 Ha en donde significan aproximadamente un $30 \%$.

\section{II.2. Características de las explotaciones de cítricos andaluzas}

\section{II.2.1. Tamaño, titularidad y dimensión económica}

Uno de los principales problemas que tiene planteado el sistema citrícola es la inadecuada estructura de las explotaciones agravado por la elevada fragmentación de las mismas (Noguera, 2010; Server, 2009). 
En 2009, el tamaño medio de la explotación de cítricos en España es de 2,78 Ha, pero menos de 5 Ha tienen el 81,19\% de las explotaciones, contabilizando solo el 29,94\% de las tierras. En Andalucía sin embargo, el tamaño medio se incrementa hasta 5,9 Ha por explotación, situándose el 71,3\% de las mismas en los tamaños inferiores a cinco Ha con sólo el $18 \%$ de la superficie. La situación andaluza se debe especialmente a la estructura de las explotaciones en la provincia de Huelva, que con el predominio de grandes propiedades sobre la base de un sector joven (Palao, 2001) alcanza una media de 17,54 Ha.

Con respecto a los cítricos ecológicos, el tamaño medio de la explotación andaluza es de $4 \mathrm{Ha}$, un poco inferior en extensión a las explotaciones convencionales, pero de nuevo esa media está condicionada por las explotaciones onubenses, que alcanzan una media de $35 \mathrm{Ha}^{7}$, mientras que en el resto de provincias no llegan a las $3 \mathrm{Ha}$ de media de explotación.

La combinación de reducido tamaño y parcelación provoca considerables dificultades a la hora de la mecanización y como consecuencia una fuerte reducción de la eficiencia en la producción y de la rentabilidad de las explotaciones, al no poder disminuir costes mediante la tecnificación. El minifundismo, no es nuevo, sino que ha sido intrínseco al sector pero gracias a los elevados márgenes de beneficio que obtenía en el pasado y al sustentarse en una agricultura de corte familiar, permitió su viabilidad y extensión, sin embargo en la actual coyuntura resulta insostenible. De hecho la continua erosión del margen de beneficio que ofrece la citricultura explica que una familia necesite hoy en día cinco veces la superficie necesaria hace 30 años para mantener una economía familiar saneada (Noguera, 2010).

Siguiendo la clasificación de las explotaciones de cítricos propuesta por Server (2009), la mayor parte de las explotaciones de cítricos andaluzas son pequeñas o muy pequeñas. En el cuadro $\mathrm{n}^{\circ} 6$ se puede apreciar que el tamaño medio de las explotaciones de cítricos convencionales en la selección realizada es de 8,04 Ha, de manera que al no considerar las explotaciones cuya SAU dedicada a cítricos es marginal hemos elevado la media de 5,92 a 8,04 Ha. Pero en el caso de las explotaciones de cítricos ecológicos el tamaño medio se reduce levemente desde 4 Ha en la información original censal a 3,47 Ha. Es decir en la producción ecológica el tamaño de las explotaciones con producciones marginales de cítricos es inferior.

Cuadro 6

DISTRIBUCIÓN DE LAS «EXPLOTACIONES CITRÍCOLAS» SELECCIONADAS SEGÚN SU TAMAÑO

\begin{tabular}{|l|r|r|r|r|}
\hline \multirow{2}{*}{ Tamaño (Ha) } & \multicolumn{2}{|c|}{ Convencional } & \multicolumn{2}{c|}{ Ecológico } \\
\cline { 2 - 5 } & Número & \multicolumn{1}{|c|}{ \% } & \multicolumn{1}{c|}{ Número } \\
\hline Menos de 1 & 1.841 & 26,31 & 118 & 27,76 \\
\hline $\mathbf{1}$ a 4,99 & 2.775 & 39,66 & 222 & 52,24 \\
\hline $\mathbf{5}$ a 9,99 & 851 & 12,16 & 36 & 8,47 \\
\hline $\mathbf{1 0}$ a 19,99 & 569 & 8,13 & 23 & 5,41 \\
\hline 20 a 49,99 & 523 & 7,47 & 22 & 5,1 \\
\hline 50 o más & 438 & 6,26 & 4 & 0,94 \\
\hline
\end{tabular}

Fuente: Microdatos del Censo Agrario (2.009). Elaboración propia.

7 Tamaño que está incluso por encima del tamaño medio de las explotaciones ecológicas europeas que es de 29,3 Ha/ explotación, aunque es casi la mitad de la media mundial 57,2 Ha/explotación (Alonso, 2003). 
En la producción convencional de cítricos las explotaciones andaluzas inferiores a $5 \mathrm{Ha}$ suman el 65,97\% del total, pero alcanzan el $80 \%$ en la práctica ecológica, lo que se completa con el hecho de que las explotaciones superiores a 50 Ha no llegan al $1 \%$ del total en práctica ecológica pero suponen el 6,26\% de las explotaciones de actividad convencional.

Respecto a la distribución de la SAU, como apreciamos en la figura 1, en esta selección de explotaciones, como cabía esperar, es mayoritaria la superficie dedicada a los cítricos, no importando el tipo de práctica, y con respecto al número de explotaciones se corrobora, lo que ya hemos comentado, que las de tamaño inferior a las 5 Ha son mayoritarias.

Figura 1

DISTRIBUCIÓN DEL NÚMERO DE EXPLOTACIONES, VOLUMEN DE HA DE CÍTRICOS Y VOLUMEN DEL RESTO DE LA SAU, SEGÚN ESCALA DE EXTENSIÓN
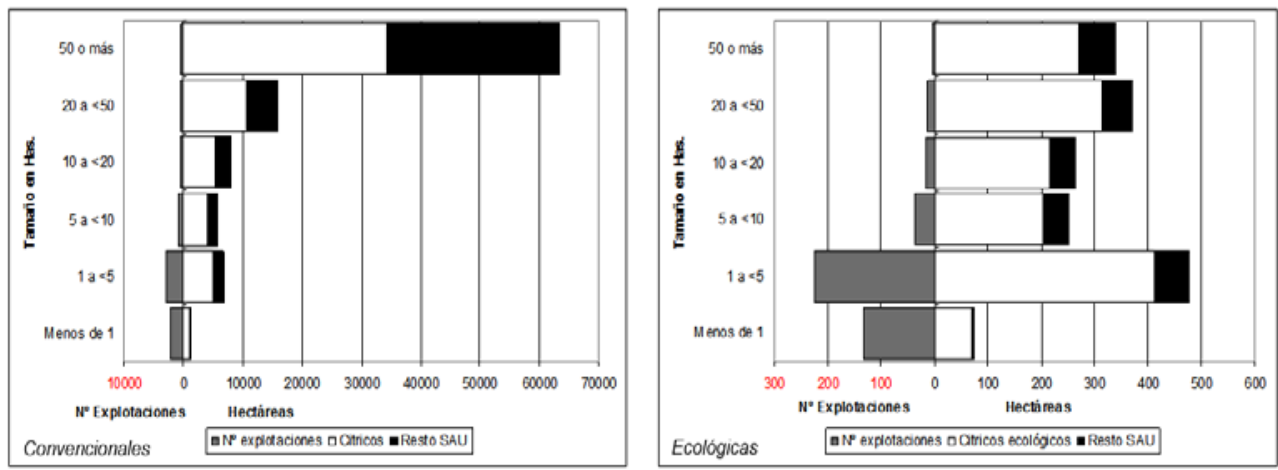

Fuente: Microdatos del Censo Agrario (2009). Elaboración propia.

Tanto en la práctica convencional como en la ecológica la personalidad jurídica del titular dominante es la persona física, casi del $100 \%$ en las menores de 5 Ha (existe un pequeño porcentaje en el intervalo de 1 a 5 Ha perteneciente a la categoría «Otra»), para ir bajando su participación progresivamente a medida que aumentamos el tamaño de la explotación, hasta perder su preeminencia en las explotaciones superiores a $50 \mathrm{Ha}$, en las que se sitúa en torno al $25-30 \%$ (Figura 2).

Otras categorías de titularidad de interés en la producción citrícola son la sociedad mercantil, dominante en todas las explotaciones superiores a $50 \mathrm{Ha}$, o la aparición de las cooperativas, más presentes en la producción ecológica, sobre todo en las explotaciones por encima de las $20 \mathrm{Ha}$, aunque en el intervalo de 10 a 19,99 Ha en esta práctica también aparece esta forma jurídica de tenencia junto a la titularidad pública, situación que no se repite en la convencional.

La mayoría de las explotaciones citrícolas en España tiene una dimensión económica muy reducida, inferior a 8 UDEs (Unidad de Dimensión Europea que equivale a 1.200 euros de margen bruto total de la explotación), por lo que son explotaciones no plenamente viables, si seguimos a Compés (2009), que consideraba viables económicamente a las que se situaban en el umbral de las 16 UDEs (19.200 euros), umbral a partir del cual Server cataloga las 

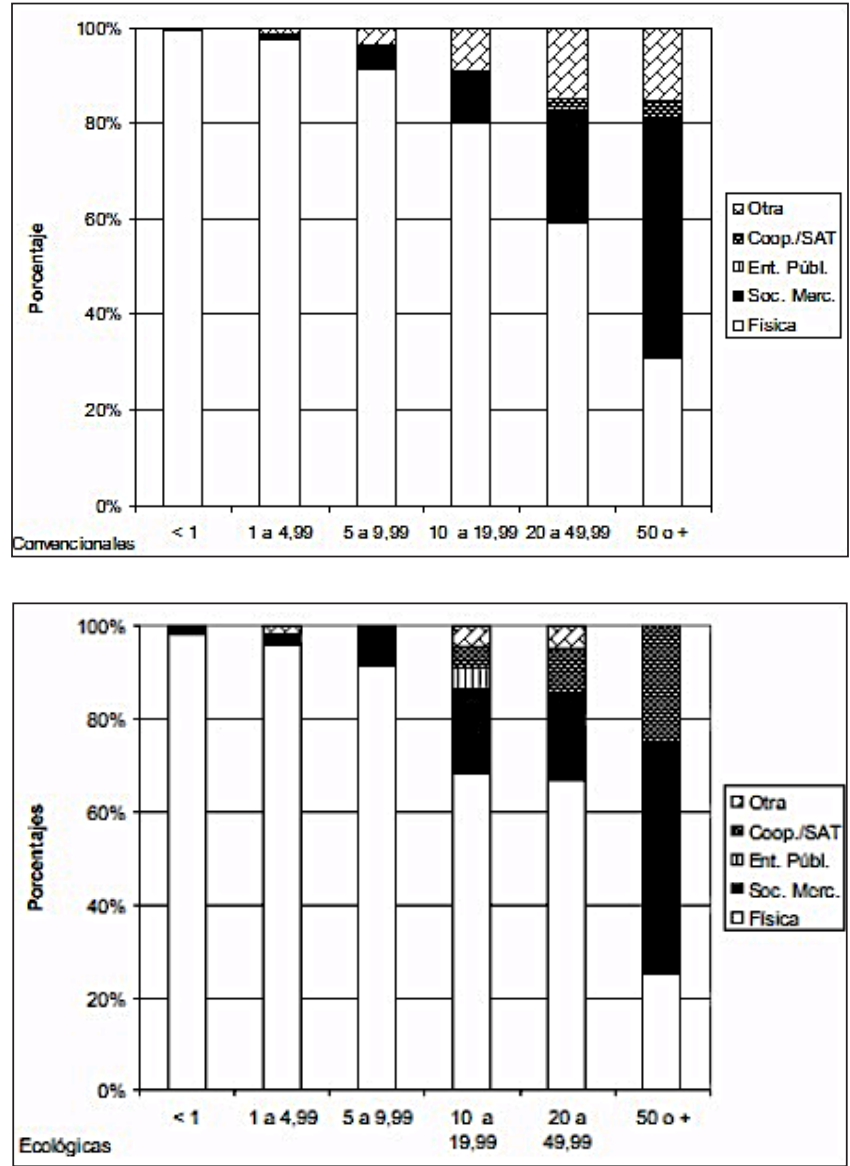

Fuente: Microdatos del Censo Agrario (2009). Elaboración propia.

explotaciones como medianas e informa de que sólo constituyen el $13.85 \%$ de las explotaciones de cítricos nacionales, y el 27,85\% de las andaluzas.

Esta panorámica de inviabilidad se completa si atendemos a la contribución al Margen Bruto del sector citrícola, pues en España las explotaciones menores de 16 UDEs $(86,15 \%)$ aportan únicamente $1 / 3$ de dicho margen mientras las explotaciones de más de 100 UDEs, que tan sólo representan el $2 \%$ del total consiguen prácticamente el mismo margen que las de pequeña dimensión (Server, 2009).

Sin embargo en Andalucía las explotaciones mayores a 100 UDEs proporcionan cerca del $62 \%$ del margen bruto total, y las menores a 16 UDEs sólo un 12\%, una situación que se debe a las reciente expansión del sector en la provincia onubense y parte de la sevillana, y por tanto no extensible a la totalidad del territorio. 
Cuadro 7

DISTRIBUCIÓN DE LAS «EXPLOTACIONES CITRÍCOLAS» SEGÚN SU DIMENSIÓN ECONÓMICA

\begin{tabular}{|l|l|r|r|r|r|}
\hline \multirow{2}{*}{ UDEs } & & \multicolumn{2}{|c|}{ Convencionales } & \multicolumn{2}{c|}{ Ecológicas } \\
\hline Menos de 8 & Muy pequeña & 55,12 & $\begin{array}{c}\% \\
\text { Margen } \\
\text { neto }\end{array}$ & $\begin{array}{c}\% \\
\text { Explotaciones }\end{array}$ & $\begin{array}{c}\% \\
\text { Margen } \\
\text { neto }\end{array}$ \\
\hline $\mathbf{8 - 1 6}$ & Pequeña & 14,46 & 4,06 & 55,40 & 11,91 \\
\hline $\mathbf{1 6 - 4 0}$ & Mediana & 13,90 & 8,79 & 23,71 & 14,99 \\
\hline $\mathbf{4 0 - 1 0 0}$ & Grande & 8,40 & 13,46 & 6,81 & 11,27 \\
\hline Más de 100 & Muy grande & 8,12 & 69,03 & 2,82 & 32,64 \\
\hline
\end{tabular}

Fuente: Microdatos del Censo Agrario (2009). Elaboración propia.

Al aplicar el análisis anterior a la selección de explotaciones de cítricos seleccionadas (Cuadro 7) observamos que no existen grandes diferencias, frente al 72,14\% de pequeñas y muy pequeñas (no viables) explotaciones convencionales que aportaba Server, nuestra selección las reduce ligeramente al 69,58\%, y en cuanto a su contribución al margen neto, también disminuye del $12,02 \%$ al 8,72\%. Como contrapartida las grandes explotaciones de más de 100 UDEs, aumentan de un 5,13\% al 8,12\%, al igual que el margen que incorporan que pasa de casi un $62 \%$ a un $69 \%$.

La comparación entre convencionales y ecológicas nos informa de una mayor presencia de las explotaciones menores de 16 UDEs en la práctica ecológica $(79,11 \%)$ que en la convencional $(69,58 \%)$, pero de una mayor contribución al margen neto de las primeras $(26,9 \%)$ sobre las convencionales $(8,72 \%)$. También es reseñable como la contribución al margen neto por parte de las explotaciones muy grandes en la práctica convencional es más del doble $(69,03 \%)$ que en la práctica ecológica $(32,64 \%)$.

Esta mayor participación en el margen neto de la < 16 UDEs en el caso de las ecológicas, que son 337 explotaciones $(26,9 \%)$, frente a $486(8,72 \%)$ de las convencionales la ponemos en relación con una mayor rentabilidad, probablemente debido al precio de venta alcanzado por los productos ecológicos ${ }^{8}$ y también por la reducción de costes por medio de una intensificación del trabajo no asalariado. Porque, según un estudio realizado para la Comunidad Valenciana sobre los cítricos ecológicos, los costes medios de producción ecológica aumentan un $25,9 \%$ en el cultivo de naranjas y un 26,9\% en mandarinas, mientras que los rendimientos disminuyen en torno a un $20 \%$ durante el período de conversión de las explotaciones desde producción convencional a ecológica, para mantenerse en los años sucesivos en torno a un $90 \%$ (Server, 2009).

8 La diferencia de precio de venta de los cítricos ecológicos en los mercados internacionales puede llegar a ser un $65 \%$ superior al que tiene los cítricos convencionales en el mismo mercado (Navarro, 2002, Domínguez, 2006). 


\section{II.2.2. El trabajo en las explotaciones}

Uno de los aspectos de las explotaciones de cítricos que complementa su acusado minifundismo ha sido que en su mayoría se han apoyado en el trabajo a tiempo parcial y de carácter familiar, aunque, como veremos, si consideramos la totalidad de las explotaciones citrícolas, el trabajo asalariado es el mayoritario.

En este contexto vamos a analizar cómo se distribuye el trabajo en las explotaciones de cítricos andaluces, aspecto muy interesante desde el momento en que sabemos que las explotaciones ecológicas tienen unos mayores costes de producción sobre la convencional y que los rendimientos son inferiores. Intentaríamos determinar sí solamente en el precio de venta radica su viabilidad o también en la utilización de una importante carga de trabajo familiar.

Para analizar este aspecto se han empleado las Unidades de Trabajo Agrarias (228 jornadas anuales), diferenciándolas entre asalariadas (fijos y eventuales) y trabajo familiar (diferenciando el del titular de la explotación y los familiares) (Cuadros 8a y b), distinguiéndose a su vez entre explotaciones con titular persona física, sociedad mercantil y el resto. Con relación a este aspecto no es posible dilucidar si los miembros de la familia realizan otra actividad económica complementaria a la explotación, al no constar esta pregunta en los Microdatos del Censo agrario de 2009.

El número de UTAs totales empleadas en las «explotaciones citrícolas» de práctica ecológica asciende a 448,037, lo que supone una ratio UTAs/Ha de SAU de 0,25; por su parte, el volumen correspondiente a las explotaciones convencionales es mucho mayor, 10.405,77, aunque la ratio desciende a 0,10 . Por tanto, efectivamente la intensidad del trabajo en las explotaciones ecológicas es superior a la registrada en aquellas otras convencionales, más del doble.

En lo relativo a la composición interna del trabajo, cuando consideramos el total de explotaciones ecológicas (última fila del cuadro 8a), se puede observar cómo algo más de la mitad de las UTAs totales $(54,05 \%)$ son realizadas por la unidad familiar, frente a un $45,95 \%$ de trabajo asalariado, que resulta ser mayoritariamente eventual. Y dentro del trabajo familiar, el reparto es prácticamente igual entre titulares y ayudas familiares, ligeramente superior el porcentaje realizado por estos últimos (27,99\% del total del trabajo de las explotaciones ecológicas).

Aunque esta es la situación general, podemos discriminar las explotaciones según su personalidad jurídica: cuando ésta es persona física, el trabajo familiar se dispara, más de las dos terceras partes de las UTAs son familiares, una vez más con un ligero sobrepeso de la ayuda familiar. Además, el trabajo contratado no llega a un tercio del total, siendo en su mayor parte eventual, con una presencia testimonial de los asalariados fijos, que no suman el $6 \%$ de las UTAs realizadas en estas explotaciones.

Esta misma distribución interna del trabajo asalariado también está presente en las explotaciones cuyo titular no es persona física, en las cuales, lógicamente, no hay trabajo familiar alguno. De las 60 UTAs correspondientes a las Sociedades Mercantiles, y las 37 de Otros tipos jurídicos, el grueso del trabajo corresponde a asalariados eventuales, mientras que los fijos suponen un 34,55\%, en las Sociedades Mercantiles, y un 25,38\% en Otros tipos jurídicos.

Si consideramos ahora a las explotaciones convencionales, puede observarse cómo cuando se las analiza en conjunto (última fila del cuadro 8b) el trabajo predominante es el asalariado $(67,04 \%)$, en fuerte contraste con la realidad de las ecológicas que hemos cifrado en $45,95 \%$. En su mayor parte este trabajo asalariado es eventual (por sí solos los eventuales 
realizan la mitad $-50,09 \%$ - del total del trabajo en las explotaciones convencionales), al tiempo que, tal y como ocurría en las ecológicas, en lo relativo al trabajo familiar el reparto es prácticamente equitativo entre jefe y ayudas familiares, también con un ligero sobrepeso de estos últimos.

Cuadro 8a

DISTRIBUCIÓN DEL NÚMERO DE UTAS SEGÚN LA PERSONALIDAD JURIDICA DEL TITULAR DE LA EXPLOTACIÓN. EXPLOTACIONES ECOLÓGICAS

\begin{tabular}{|l|r|r|r|r|r|r|r|}
\hline \multirow{2}{*}{$\begin{array}{c}\text { Personalidad } \\
\text { Jurídica }\end{array}$} & Total & \multicolumn{3}{|c|}{ UTAs contratadas } & \multicolumn{3}{c|}{ UTAs No contratadas } \\
\cline { 3 - 8 } PTAs & Asalariados & A. Fijos & A. Eventuales & Total & Titular & Familiares \\
\hline \multirow{2}{*}{ Persona Física } & 349,81 & 107,66 & 20,14 & 87,51 & 242,15 & 116,76 & 125,38 \\
& $100 \%$ & $30,78 \%$ & $5,76 \%$ & $25,02 \%$ & $69,22 \%$ & $33,3 \% 8$ & $35,84 \%$ \\
\hline Sociedad & 60,63 & 60,63 & 20,94 & 39,68 & 0 & 0 & 0 \\
mercantil & $100 \%$ & $100 \%$ & $34,55 \%$ & $65,45 \%$ & & 0 & 0 \\
\hline \multirow{2}{*}{ Resto } & 37,59 & 37,59 & 9542 & 28,04 & 0 & 0 & 0 \\
& $100 \%$ & $100 \%$ & $25,38 \%$ & $74,62 \%$ & & & \\
\multirow{2}{*}{ Total } & 448,03 & 205,88 & 50,63 & 155,25 & 242,15 & 116,76 & 125,38 \\
& $100 \%$ & $45,95 \%$ & $11,30 \%$ & $34,65 \%$ & $54,05 \%$ & $26,06 \%$ & $27,99 \%$ \\
\hline
\end{tabular}

Fuente: Microdatos del Censo Agrario (2009). Elaboración propia.

Cuadro 8b

DISTRIBUCIÓN DEL NÚMERO DE UTAS SEGÚN PERSONALIDAD JURÍDICA DEL TITULAR DE LA EXPLOTACIÓN. EXPLOTACIONES CONVENCIONALES

\begin{tabular}{|l|r|r|r|r|r|r|r|}
\hline \multirow{2}{*}{$\begin{array}{c}\text { Personalidad } \\
\text { Jurídica }\end{array}$} & Total & \multicolumn{3}{|c|}{ UTAs contratadas } & \multicolumn{3}{c|}{ UTAs No contratadas } \\
\cline { 3 - 8 } & UTAs & Asalariados & A. Fijos & A. Eventuales & Total & Titular & Familiares \\
\hline Persona & $4.806,62$ & $1.377,14$ & 239,30 & 113783 & $3.429,48$ & $1.632,61$ & $1.796,86$ \\
Física & $100 \%$ & $28,65 \%$ & $4,98 \%$ & $23,67 \%$ & $71,35 \%$ & $33,97 \%$ & $37,38 \%$ \\
\hline Sociedad & $4.311,23$ & $4.311,23$ & $1.087,96$ & $3.223,27$ & 0 & 0 & 0 \\
mercantil & $100 \%$ & $100 \%$ & $25,23 \%$ & $74,77 \%$ & & & 0 \\
\hline \multirow{2}{*}{ Resto } & $1.287,90$ & $1.287,90$ & 436,85 & 851,05 & 0 & 0 & 0 \\
& $100 \%$ & $100 \%$ & $33,92 \%$ & $66,08 \%$ & & & \\
\hline \multirow{2}{*}{ Total } & $10.405,77$ & $6.976,29$ & $1.764,12$ & $5.212,16$ & $3.429,48$ & $1.632,61$ & $1.796,86$ \\
& $100 \%$ & $67,04 \%$ & $16,95 \%$ & $50,09 \%$ & $32,96 \%$ & $15,69 \%$ & $17,27 \%$ \\
\hline
\end{tabular}

Fuente: Microdatos del Censo Agrario (2009). Elaboración propia.

Discriminando una vez más las explotaciones según su personalidad jurídica, cuando ésta es persona física la distribución interna de las UTAs es muy similar a la correspondiente a las ecológicas, es decir predomina el trabajo familiar, aunque en este caso con una mayor representación de la ayuda familiar, al tiempo que en lo relativo a los asalariados, son básicamente eventuales, con unos fijos que no alcanzan un 5\% del trabajo realizado en ellas. También, por 
tanto, son explotaciones que se corresponden con una dinámica de agricultura familiar, con contratos de trabajo básicamente eventual y destinado a cubrir aquellas labores, o aquellos momentos puntuales del ciclo productivo, en los que la capacidad familiar es desbordada.

También muy similar a la situación del ecológico es la correspondiente a las restantes figuras jurídicas, en las que es mayoritario el empleo asalariado eventual, por encima del $66 \%$, aunque, mayor en el caso de las sociedades $(74,7 \%)$.

Por otro lado, no escapa a nadie que la composición del trabajo está fuertemente influenciada por el tamaño de las explotaciones, que puede medirse a través de su dimensión económica. Y para mostrar esta variación, y su evolución temporal, en el caso de explotaciones con titular persona física, vamos a recurrir a un método gráfico propuesto por Ruiz-Maya (1989), que, si bien es cierto que reduce la información, tiene la inestimable virtud de mostrar de forma sencilla las diferentes situaciones del trabajo en la explotación con titular persona física. El procedimiento consiste en llevar a semiejes cartesianos la participación porcentual de los cuatro tipos de trabajo identificados (empresario, ayuda familiar, asalariado fijo y asalariado eventual) para cada intervalo de tamaño de UDEs considerado. En la parte positiva del eje de abcisas se sitúa el porcentaje que sobre el trabajo total representa el empresario persona física. En la parte positiva del eje de ordenadas, el peso de la ayuda familiar, situando el trabajo asalariado fijo en la parte negativa del eje de abcisas y el asalariado eventual en la parte negativa del de ordenadas. Se obtiene, así, para cada dimensión económica cuatro puntos, uno para cada tipo de trabajo; y con el fin de simplificar la lectura de dicha información, se calcula el centro de gravedad de los cuatro, que será el que finalmente se representa en el gráfico.

La interpretación de la situación de los centros de gravedad en cada uno de los cuatro cuadrantes responde a las situaciones que se ofrecen en la figura 3, tal como señala el mencionado autor.

Figura 3

TRABAJO Y DIMENSIÓN ECONÓMICA EN LAS EXPLOTACIONES AGRARIAS

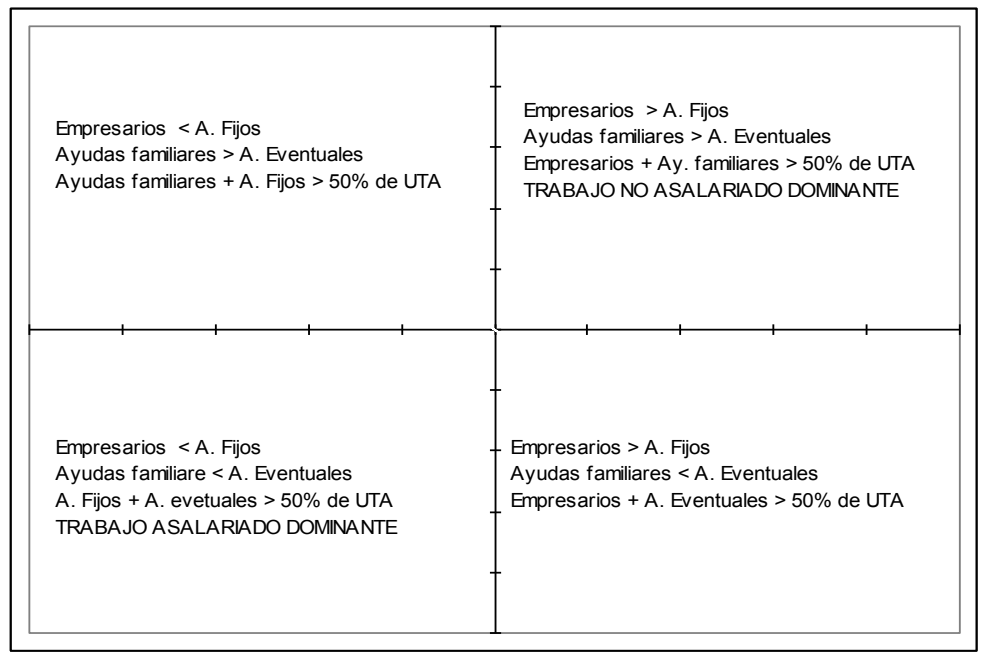

Fuente: Ruiz-Maya, 1989. 
Para evaluar la relación entre trabajo y dimensión económica, vamos a emplear los cinco intervalos de UDEs, anteriormente utilizados (Cuadro 6), aunque por debajo de las 16 UDEs el factor trabajo se considera que no se remunera igual que en el resto de sectores, al igualar o superar la renta de referencia (Ramos, 1999).

La información representada en la figura 4 muestra con claridad varias cosas. En primer lugar, que en ninguno de los tamaños económicos de explotación, ya sean correspondientes a la citricultura ecológica o a la convencional, cuando el titular es persona física, predomina el trabajo asalariado. Tan sólo el intervalo que agrupa a las explotaciones convencionales de mayor tamaño está cerca del predominio de este trabajo no familiar. Y junto a este intervalo, tan sólo en las ecológicas más grandes y en las convencionales de entre 40 y 100 UDEs son los eventuales y los titulares los que realizan el grueso del trabajo, en el resto, sin importar el tipo de práctica, el predominio corresponde al trabajo familiar.

Figura 4

EXPLOTACIONES CON TITULAR PERSONA FÍSICA. DISTRIBUCIÓN DE LOS TIPOS DE UTAS SEGÚN LA DIMENSIÓN ECONÓMICA DE LAS EXPLOTACIONES EN UDES

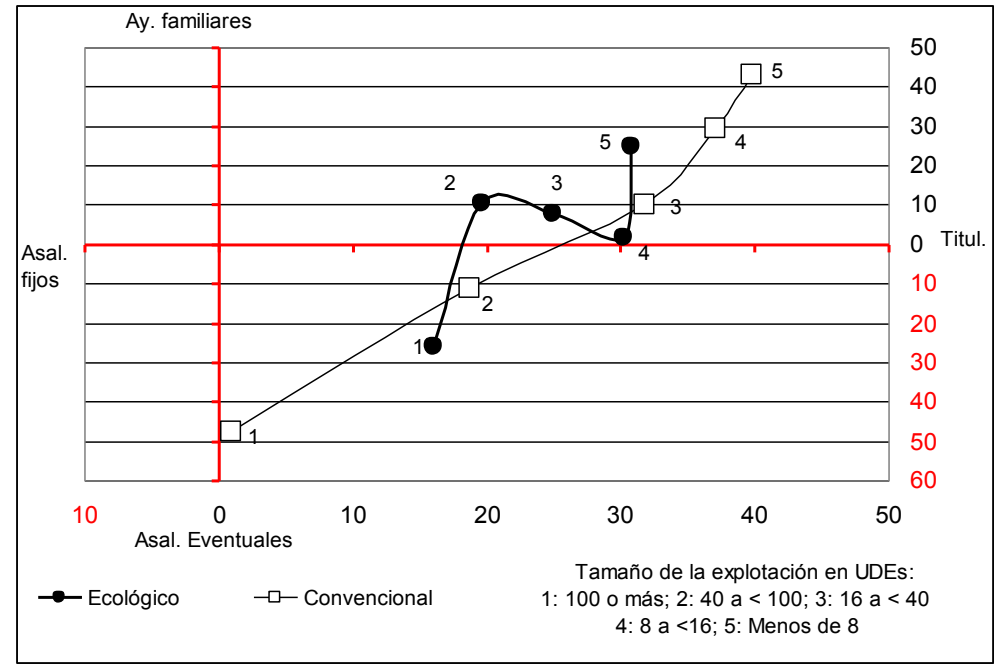

Fuente: Microdatos del Censo Agrario (2009). Elaboración propia.

No obstante, de la lectura de las curvas se desprenden realidades algo diferentes, según sea el tipo de explotación. Es así que cuando nos referimos a las explotaciones convencionales, la tendencia es la que cabría esperar. Tan sólo las más grandes (de 40 UDEs o más) tienen alguna capacidad para demandar trabajo externo, con más fuerza cuando mayor es el tamaño de la explotación, al tiempo que por debajo de las 40 UDEs el trabajo familiar es mayoritario, directamente proporcional a la disminución del tamaño de la explotación, como reflejo de la incapacidad no tanto de generar empleo, sino de remunerarlo, por lo que son las ayudas familiares las que lo realizan. 
Pero cuando analizamos la curva de las explotaciones ecológicas, si bien es cierto que son las mayores de 100 UDEs las únicas en las que la suma del trabajo realizado por el titular y los asalariados eventuales es mayoritaria, y que en el resto de intervalos predomina el trabajo familiar, la relación entre tamaño económico y peso de este no muestra una tendencia tan clara como la existente en el caso de las explotaciones convencionales.

En las explotaciones ecológicas entre 8 y 100 UDEs, cuanto menor es el tamaño, mayor es la proporción de trabajo realizado por los titulares, que sólo es complementado por la ayuda familiar. No obstante, conforme se reduce el tamaño de la explotación, junto a este aumento del trabajo del titular se registra, por un lado, un descenso del porcentaje de trabajo realizado por las ayudas familiares, combinado con tan solo ligero aumento del volumen de UTAs correspondientes a los asalariados eventuales. Así su trabajo es el 25,07\% en las explotaciones de entre 40 y 100 UDEs, y del 27,86\% en las comprendidas entre 8 y 16 UDEs, mientras que la participación de los ayudas familiares es respectivamente del 35,5\% y el 29,59\%.

Por último, en las explotaciones más pequeñas la mayor parte del trabajo es familiar, con una presencia muy minoritaria de los asalariados, pero aún superior a la correspondiente a las explotaciones convencionales del mismo tamaño.

Por tanto, la proporción de trabajo asalariado en las explotaciones ecológicas es mayor que el correspondiente a las convencionales aún cuando el trabajo familiar es mayoritario. El por qué probablemente deba buscarse no tanto en la capacidad para pagar rentas de las primeras, como en la especificidad de determinadas tareas que deben llevarse a cabo en las ecológicas con el objetivo de obtener, y mantener la certificación.

\section{III.3. Clasificación de las explotaciones de cítricos cuyo titular es persona física}

Un paso más para avanzar en las características principales de las explotaciones de cítricos andaluzas lo constituye la realización de una clasificación de aquellas cuyo titular es persona física, para lo que emplearemos diferentes métodos de análisis multivariante. La clasificación la hemos realizado a través de un cluster de $\mathrm{k}$ medias, y, como paso previo, hemos realizado un análisis de componentes principales, que nos aportará las variables con las que alimentaremos el análisis de conglomerados. En este sentido, la realización de un análisis factorial presenta ciertas ventajas a la hora de obtener variables para la realización de un análisis de conglomerados, puesto que el número final de las mismas es pequeño (tantas como componentes principales se deriven del factorial), están en la misma unidad de medida y no están correlacionadas. Y con ello nos aseguramos de que cumplen los requisitos necesarios para su correcta aplicación en un análisis Cluster (Díaz de Rada, 2002).

Son siete las variables sobre las que hemos realizado el análisis de componentes principales: dimensión física de la explotación (tamaño total), dimensión explotada (SAU), dimensión económica de la explotación (UDEs), productividad (PET ${ }^{9} / \mathrm{UTA}$ ), UTAs asalariadas, UTAs familiares y UTAs dedicadas por el titular a su explotación. Como puede observarse, hemos extraído información de la práctica totalidad de bloques que aportan variables numé-

9 La producción estándar total (PET) de la explotación equivale a la suma de los valores obtenidos para cada característica agrícola multiplicando las producciones estándares (valor monetario de la producción correspondiente a la situación media de una determinada región para cada característica agrícola) por unidad por el número de unidades correspondientes. 
ricas de los Microdatos censales, excluyendo la ofrecida en intervalos ${ }^{10}$. En este sentido, es necesario recordar que el cuestionario censal no ofrece información alguna acerca de la maquinaria, el tipo de riego, etc. empleados en la explotación, por lo que estos aspectos no han podido ser integrados en el análisis.

En el caso de las 6.696 explotaciones convencionales consideradas, el análisis de componentes principales ha identificado dos, que hemos denominado «tamaño» y «mano de obra externa», y que en conjunto explican el $70,44 \%$ del total de la varianza. Por su parte, son tres los componentes que el análisis ha identificado en el caso de las 394 explotaciones ecológicas, denominados, a partir de las variables que les aportan significado, «tamaño», «trabajo generado» y «dedicación del titular a la explotación», que en conjunto explican el $86 \%$ de la varianza total.

Los resultados de ambos análisis son muy similares, puesto que tanto en las explotaciones ecológicas como en las convencionales el principal componente es el que hemos identificado como tamaño, al que aportan significado las dimensiones física y económica de la explotación, la superficie total utilizada y la productividad. En el caso de las ecológicas este componente explica el 50,45\% de la varianza, y en el de las convencionales el 44,17\%. La diferencia entre ambos grupos de explotaciones se encuentra en el hecho de que el análisis ha unido las tres variables correspondientes al trabajo en un único componente en el caso de las convencionales, mientras que en las ecológicas ha individualizado las jornadas del titular en un componente aparte, que da cuenta de algo más del 15\% de la varianza total explicada.

Una vez realizado este análisis, hemos procedido a agrupar a las explotaciones a partir de las puntuaciones obtenidas en los componentes que el análisis anterior ha ofrecido, seleccionando un método de agrupamiento no jerárquico, en concreto el de k medias. Como es sabido, la finalidad de los métodos de agrupamiento no jerárquicos es realizar una agrupación excluyente maximizando la varianza intergrupos y minimizando la intragrupos, sin que las clases resultantes estén organizadas jerárquicamente ni relacionadas entre sí. El número de grupos óptimo en los que el análisis dividirá los casos debe ser seleccionado por el investigador, y en nuestro caso serán 4 grupos para las explotaciones convencionales y 3 para las ecológicas.

En el caso de las explotaciones citrícolas convencionales el Grupo 1 tiene 2 explotaciones (0,03\% del total), el Grupo 2 reúne 45 explotaciones (0,67\%), el Grupo 3, el más numeroso, con 5.520 explotaciones $(82,43 \%$ del total) y el Grupo 4, agrupa las 1.429 restantes, el $21,34 \%$.

Por su parte, el Primer grupo de las «explotaciones citrícolas» ecológicas contiene 25 explotaciones (6,34\% del total), el Segundo, el más numeroso, 350 (88,83\% del total), y el Tercero 19, que suponen el $4,82 \%$ restante.

De la homogeneidad interna de los agrupamientos da cuenta la información que aportamos en los gráficos de caja y bigotes, en los que hemos representado la distancia de cada una de las explotaciones al centroide del cluster al que pertenece (Figura 5). En ellos debe destacarse las reducidas dimensiones de las cajas y del recorrido de los bigotes de los clústeres mayoritarios ( 3 y 4 en las convencionales, 2 en las ecológicas), lo que da cuenta de la homogeneidad interna de los mismos.

10 Como la edad del jefe de la explotación, que no se ofrece en número de años, sino referida a intervalos decenales. 
Figura 5

CAJAS Y BIGOTES DE LA DISTANCIAAL CENTRO INICIAL DE CLASIFICACIÓN
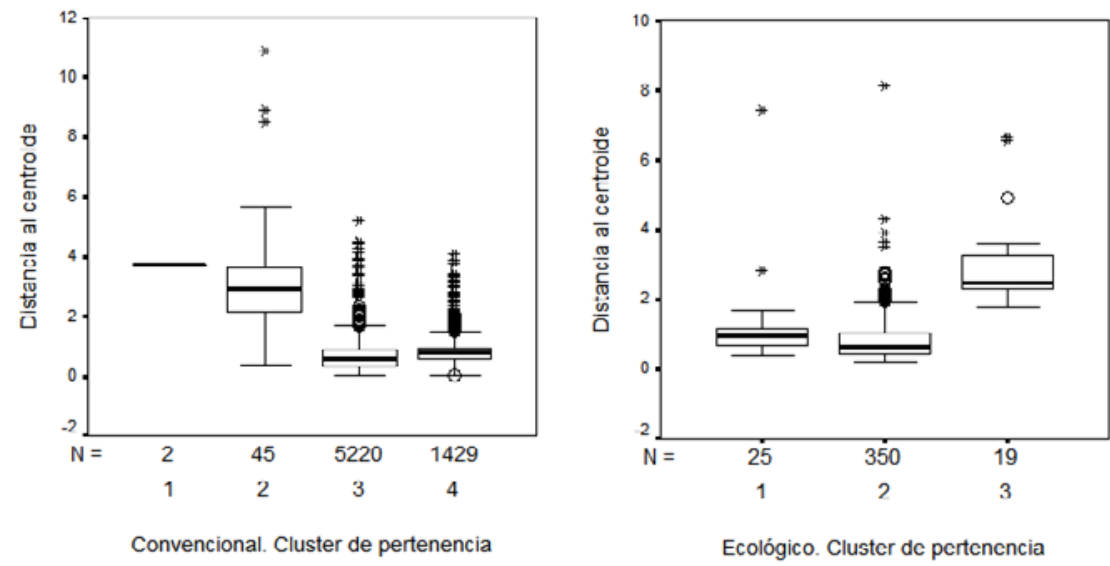

Fuente: Microdatos del Censo Agrario (2009). Elaboración propia.

Para facilitar la lectura de las características de estos grupos hemos elaborado dos gráficos en los que representamos los centros de los conglomerados finales (Figura 6).

En el correspondiente a las convencionales vemos cómo las características del cluster 3 , el que agrupa a 4 de cada 5 de estas explotaciones indica que las mismas son comparativamente de pequeño tamaño (su media de SAU es de sólo 2,89 Ha) y, en consecuencia, la capacidad para contratar mano de obra externa también es reducida (el porcentaje medio de UTAs asalariadas sobre el total de UTAs de la explotación es de un exiguo 8,56\%). Es por ello que las barras de ambos componentes presentan puntuaciones negativas en este grupo. Estas son características opuestas a las correspondientes al grupo 4 que, recordemos, agrupa el $25 \%$ de las explotaciones convencionales: son explotaciones de un tamaño mayor (12,89 Ha de SAU de media), pero en las que una porción significativa del trabajo es realizado por asalariados, en promedio el 38,45\%, asalariados eventuales en su mayor parte. Por último, las 45 explotaciones agrupadas en el cluster 2 son las de mayor tamaño (su media de SAU es de $168 \mathrm{Ha}$ ), y también aquellas en las que se ha detectado una mayor capacidad para contratar mano de obra asalariada (el porcentaje medio de UTAs asalariadas sobre el total de UTAs asciende al 59,98\%), lo que está en lógica consonancia con la demanda de trabajo que genera su tamaño.

Si nos centramos ahora en el gráfico correspondiente a las explotaciones ecológicas, se puede apreciar cómo la característica básica del segundo conglomerado, en el que, recordemos, se encuentra el grueso de las explotaciones, es el reducido tamaño de las mismas -tanto físico como económico, 1,7 Ha de SAU y tan sólo 7,42 UDEs-, que redunda en unas necesidades de trabajo también muy reducidas. Un trabajo ejecutado de forma mayoritaria por el titular de la explotación, que no es apoyado por ayudas familiares o asalariados, bien porque la explotación no lo necesita, bien porque las cuentas no permiten la contratación, ni siquiera sea a tiempo parcial, de mano de obra ajena a la familia. 
Por su parte, las explotaciones incluidas en los conglomerados 1 y 3 se caracterizan comparativamente por un gran tamaño -mayor en el tercer conglomerado $(18,48$ Ha de SAU en promedio) que en el primero (7,5 has)-, pero aquí terminan las coincidencias entre ambos.

Las explotaciones incluidas en el tercer conglomerado requieren de una alta dedicación laboral de sus titulares (en 12 de las 19 existentes el titular trabaja de 330 jornadas o más a tiempo completo ), pero además, la carga de trabajo que generan no puede ser totalmente cubierta por el titular, de forma que deben acudir al trabajo realizado tanto por ayudas familiares como por asalariados, características que quedan registradas en el importante tamaño de las barras correspondientes a los componentes trabajo y dedicación del jefe.

En contraste, las 25 explotaciones incluidas en el primer conglomerado no presentan la correlación entre tamaño y carga de trabajo asociada a él que acabamos de mostrar. Es más, el trabajo que se realiza en ellas es muy escaso (las barras de los componentes anteriores tienen también una longitud reseñable, solo que en este caso los valores son negativos). Según la información consignada en el Censo: sólo en tres de las 25 explotaciones de este grupo el titular le dedicó más de 100 jornadas (y nunca más de 120), mientras que en 8 trabajó menos de 5. Y esta escasísima dedicación de los titulares a unas explotaciones grandes en el contexto en el que nos movemos no es compensada por el trabajo realizado ni por los asalariados (únicamente en 7 se consignaron UTAs asalariadas) ni por ayudas familiares (tan sólo en 3 se indicó su existencia, por cierto, coexistiendo con UTAs asalariadas). Cabe plantearse, por tanto, quién trabaja en estas explotaciones, si es que están abandonadas, o bien se encuentran en proceso de conversión desde el cultivo convencional.

Figura 6

EXPLOTACIONES DE CÍTRICOS. CENTROS DE LOS CONGLOMERADOS FINALES
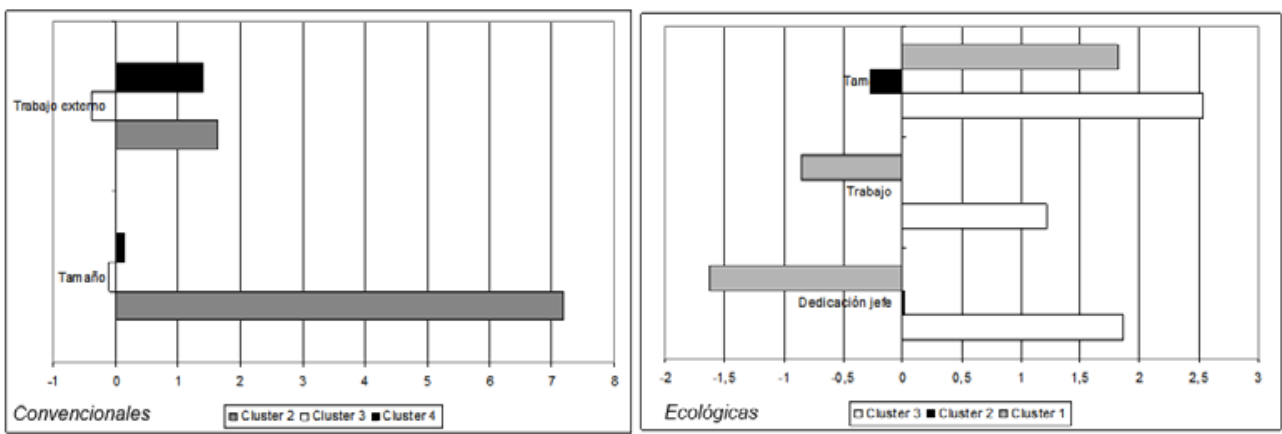

Fuente: Microdatos del Censo Agrario de 2009. Elaboración propia.

\section{CONSIDERACIONES FINALES}

El creciente interés por el medioambiente ha llevado consigo un mayor acercamiento a la llamada agricultura orgánica o ecológica y ello, no sólo porque es una forma de producir respetuosa con el medioambiente sino que, además, atiende mejor a los requerimientos sobre salud alimentaria que cada día en mayor medida preocupa a los consumidores. A lo que hay que añadir, el papel que ha jugado la Política Agraria desarrollada en las últimas 
décadas por la Unión Europea, especialmente a partir de la reforma de 1992, que introdujo las medidas de acompañamiento relativas al medioambiente favoreciendo la toma en consideración de la AE dentro del marco de la Política Agraria y de Desarrollo Rural de la UE.

Este conjunto de aspectos ha contribuido a que los productores agrarios hayan manifestado su interés por este tipo de prácticas, consciente de que responden mejor a las nuevas demandas sociales y que van a contar con un apoyo económico por parte de la Administración. En este sentido la AE ha venido disfrutando por parte de la UE de un marco normativo donde se recogía el régimen de ayudas dirigidas a estas prácticas de cultivos. En el caso de la Comunidad Autónoma Andaluza, la Administración ha apostado con claridad por estas prácticas a través de la elaboración de los Planes Andaluces de AE, donde se definen las prioridades del sector, se establecen líneas de actuación y se dotan de presupuesto para su desarrollo.

La evolución de la AE desde sus inicios ha estado bastante influenciada por el establecimiento de este apoyo institucional. En la actualidad el régimen de ayuda que se gestione será un factor importante de cara a la continuidad futura de este sistema agrícola en el marco de una política agroambiental y de desarrollo rural más comprometida con esta forma de producción, y pueda contribuir a incrementar la viabilidad del cultivo orgánico frente al tradicional. Pero en este punto, debemos señalar que las ayudas suelen ser muy limitadas, ante la pérdida de beneficios que supone el período de reconversión, la ingente burocracia en la solicitud de las ayudas, a lo que hay que añadir en el caso de los cítricos, el reducido tamaño de las explotaciones. A pesar de todas las dificultades para su desarrollo, hoy en día, la AE es ya una realidad consolidada en España, donde ha experimentado, como hemos visto, una evolución espectacular, tanto en superficie cultivada como en número de operadores. Igualmente, hay que resaltar que se ha producido cambios en su estructura espacial, pues de ser Cataluña el principal referente es ahora Andalucía la que ocupa la posición más relevante, al aportar casi el 55\% de la superficie total. Asimismo, conforme se ha ido afianzando la AE, se han ido consolidando los grupos de cultivos pioneros, a la vez que incorporándose otros nuevos. En este sentido, hemos podido comprobar que son prados, praderas y forrajes los más tradicionales, los que más superficie ocupan (55\%), y a su vez los responsables del incremento superficial de la $\mathrm{AE}$ en este período. La principal razón se basa en las extraordinarias dificultades, especialmente normativas, que supone transformar parte de la explotación en ecológico, y al ser estas fincas de gran tamaño no tiene sentido y sí muchas dificultades convertir sólo una parte de las mismas, como puede ocurrir en otros cultivos con explotaciones de menor tamaño (hortofrutícolas), por lo que se opta por su conversión total (Alonso, 2003).

Frente a ellos, el cultivo de cítricos tiene una mínima contribución $(0,35 \%)$, si bien resulta significativo que el 63,1\% de esta superficie se sitúe en Andalucía, seguida a gran distancia por la Comunidad Valenciana (16\%). Esta pequeña cifra que presenta todavía la citricultura ecológica se debe a que los problemas de infraestructuras existentes en muchas zonas productoras dificultan bastante el poder mantener una rentabilidad aceptable, tales como: los menores rendimientos productivos y los costes de cultivos más elevados que no se ven siempre compensados con el precio que paga el consumidor y con las ayudas arbitradas para el sector, la falta de asesoramiento y formación sobre el cultivo de los cítricos que conduce a una baja profesionalización y un aumento de la problemática productiva 
(mayores problemas de plagas, disminución inicial de la producción, etc); la información negativa en torno a una mayor dificultad en el manejo de las explotaciones ecológicas frente a la facilidad en el manejo de los cítricos convencionales; la actitud conservadora que siempre ha caracterizado a los agricultores frente a las innovaciones, etc.

Tradicionalmente, uno de los principales problemas que ha tenido el cultivo de los cítricos en España ha sido el de su ineficiente estructura productiva caracterizada por un acusado minifundismo. Ante ello resulta muy oportuno comparar las estructuras productivas de los dos sistemas citrícolas. La comparación de los parámetros que nos han permitido los microdatos del último Censo Agrario han puesto de manifiesto que, en líneas generales, los problemas estructurales que arrastran las explotaciones citrícolas convencionales se siguen manteniendo en las ecológicas. Si bien, en algunos aspectos puntuales presentan algunas diferencias que junto a los resultados económicos mejores que se alcanzan en la venta del producto, pueden convertir estas prácticas en una opción real para la citricultura.

En esta comparación, el primer aspecto que podemos resaltar es que el tamaño medio de las explotaciones de cítricos ecológicos en Andalucía es inferior a las convencionales: las explotaciones convencionales duplican las ecológicas, por lo que a priori, cabe indicar que el hándicap que supone este aspecto en el funcionamiento de las mismas se agrava en el marco ecológico. En general una de las razones de este menor tamaño se debe a la conversión gradual de las fincas a este tipo de manejo; generalmente se tiende a iniciar la transformación a AE de una parte de la finca, de manera que en años sucesivos se va incorporando el resto de superficie al manejo ecológico, por lo que es de esperar que en un futuro se produzca un ligero aumento del tamaño medio de las explotaciones.

Aunque esta desventaja queda aminorada cuando se comprueba que las explotaciones de los tamaños inferiores aumentan respecto a las convencionales su margen neto, probablemente debido al precio de venta alcanzado por los productos ecológicos, por la reducción de costes por medio de una intensificación del trabajo no asalariado y por las mejores posibilidades de comercialización. En cambio en los tamaños superiores la situación cambia (mayores a $50 \mathrm{Ha}$ ), siendo la mitad de las convencionales, probablemente debido a la mayor intensidad de contratación de mano de obra asalariada que requieren estos tamaños productivos, ante las que no puede responder la unidad familiar.

El segundo aspecto a resaltar se relaciona con la intensidad del trabajo, habiéndose comprobado por un lado que las explotaciones de cítricos ecológicos requieren una mayor densidad de mano de obra, más del doble que las convencionales, y por otro que en las explotaciones citrícolas ecológicas es menos frecuente el trabajo asalariado, siendo prioritaria la fuerza de trabajo que proviene de la unidad familiar.

La capacidad y composición del trabajo invertido en la explotación depende en gran medida de su tamaño. En este aspecto no se han encontrado notables diferencias entre las explotaciones ecológicas y las convencionales. Partiendo de la base de que en ningún tamaño de explotación se impone el trabajo asalariado sobre el de la unidad familiar (salvo en las de gran tamaño), hay que señalar algunas diferencias entre las explotaciones convencionales y las ecológicas. En las primeras, cuanto mayor es el tamaño de la explotación mayor capacidad posee de demandar trabajo externo; en las segundas, las ecológicas, a menor tamaño demanda algo más de trabajo que las explotaciones convencionales, lo que corrobora la especificidad de las labores aplicadas. 
A modo de conclusión podemos apuntar que este modelo de producción ha supuesto una alternativa clara para muchos productores de cítricos y es un método de producción muy adecuado para sustentar las pequeñas y medianas explotaciones familiares que produzcan productos de calidad. Asimismo conviene subrayar que la citricultura orgánica muestra un crecimiento que, en nuestra opinión, se mantendrá en los próximos años, si bien su ritmo de crecimiento dependerá de la evolución del mercado en términos de preferencia por lo orgánico, con mayores garantías sanitarias y medioambientales, y en cómo se traduzca en la práctica el apoyo institucional a esta forma de agricultura.

\section{BIBLIOGRAFÍA}

ALONSO, A.M. (2003): «La estructura productiva de la AE», www. Agroinformacion.com.

ALONSO, A.M., GONZÁLEZ, R, FORASTER, L. (2008): «Comparación económica entre cultivos ecológicos y convencionales». VIII Congreso de la Sociedad Española de AE. 16-20 septiembre 2008, Bullas (Murcia).

CADENAS MARÍN, A. (1995): El concepto de desarrollo sustentable, los principios de sustentabilidad y las posibilidades para la agricultura y el medio rural, Agricultura y Desarrollo sostenible. Serie Estudios. MAPA. Madrid.

COMISIÓN EUROPEA (2000): Agricultura Ecológica. Luxemburgo.

COMISIÓN EUROPEA, COORDINADORA DE ORGANIZACIONES DE AGRICULTORES Y GANADEROS-COAG (2006): «De la producción agraria convencional a la ecológica». Proyecto cofinanciado por la Comisión Europea: Programa de medidas de información de la PAC 2006 y COAG (Coordinadora de organizaciones de agricultores y ganaderos).

COMPÉS LÓPEZ, R., Y GARCÍA ÁLVAREZ COQUE, J. M. (2009): La reforma de la PAC: alternativas y oportunidades para España. Documento de Trabajo 4/2.009. Fundación Alternativas.

DUESTERHAUS, R. (1990): Sustainability's promise. Journal soil and water conservation (jan-feb 1.990). $45 \mathrm{pp}$

DIAZ DE RADA IGÚRQUIZA, V. (2002): Técnicas de análisis multivariante para investigación social y comercial. Ed. Ra-Ma, Madrid.

DOMINGUEZ GENTO A (2006): La citricultura ecológica. Consejería de Agricultura y Pesca, Junta de Andalucía. Sevilla.

IFOAM (FEDERACIÓN INTERNACIONAL DE MOVIMIENTO DE AE) (1990): Normativa de la federación internacional de movimientos de $A E$. Integral monográfico, $\mathrm{n}^{\circ} 1$. Barcelona.

JULIÁ IGUAL, J.F., SERVER IZQUIERDO, R.J. (2004): Evaluación económico-financiera de cultivo en cítricos ecológicos (orgánicos) versus convencionales, FAO/http//www.fao. org., $50 \mathrm{pp}$.

JUNTA DE ANDALUCÍA (2002-2006): I Plan andaluz de AE. Consejería de Agricultura y Pesca. Sevilla.

JUNTA DE ANDALUCÍA (2007-2013): II Plan andaluz de AE. Consejería de Agricultura y Pesca. Sevilla. 
JUNTA DE ANDALUCÍA (2013): «Jornadas provinciales para la elaboración del III Plan andaluz de AE (Julio, 2013)». Consejería de Agricultura y Pesca. Sevilla.

JUNTA DE ANDALUCÍA (2011): Competencia y cadena de valor en la producción y distribución de cítricos. Agencia de defensa de la competencia de Andalucía. Consejería de Economía, Innovación y Ciencia. Sevilla.

LABRADOR, J. y GUIBERTEAU, A. (1991): La AE. Hojas divulgadoras, núm.11/90 HD. Ministerio de Agricultura, Pesca y Alimentación, Madrid, 31 pp.

LABRADOR, J.; REYES, J. L.; PORCUNA, J. L. y SÁNCHEZ, J. G. (1999): Guía de la AE en la Comunidad Valenciana. Seminario de AE, Valencia, 179 pp.

LARRUBIA VARGAS, R. (1998): La agricultura en Málaga a finales del S.XX. Nuevas orientaciones productivas. SPICUM (Servicio de publicaciones de la Universidad de Málaga).

LOWE PHILIP; WEIL WARD (1994): «Agricultura y medio ambiente: temario sociológico». Agricultura y Sociedad n ${ }^{\circ} 71,260 \mathrm{pp}$.

NAVARRO ROGRÍGUEZ S.R., LARRUBIA VARGAS, R. (2002): «La AE: producción y comercialización en la provincia de Málaga». Baetica $\mathrm{n}^{\circ}$ 24, 113-147.

NOGUERA TUR, J. (2010): «Viabilidad y competitividad del sistema citrícola valenciano». Boletín de la Asociación de Geógrafos Españoles, n 52, 82-99.

PALAO TABOADA, F., MÁRQUEZ DOMINGUEZ, J.A. (2001): Posibilidades logísticas para el tráfico de cítricos y fresas por el Puerto de Huelva, Fundación El Monte, Huelva.

PORCURA COTO J.L., et ali (2010): Guía de la AE de cultivos hortícolas al aire libre. Federación de cooperativas agrarias de la comunidad de Valencia. Proyecto Mayas.

RAMOS, R. GALLARDO E. (1999): «Disparidades de la agricultura española entre la modernización y las nuevas funciones del territorio». Revista de Estudios Regionales $\mathrm{n}^{\circ}$ 54, 17-46.

RODRÍGUEZ MEDINA, C. (2002): «El interés de la Unión por una producción agrícola ecológica». En Actas del XI Coloquio de Geografía Rural: Los espacios rurales entre el hoy y el mañana. Universidad de Cantabria. Santander.

RUIZ-MAYA, L. (1989): «El trabajo en las explotaciones agrarias: la influencia de la dimensión económica en la evolución de la estructura del trabajo». Revista de Estudios AgroSociales, $\mathrm{n}^{\mathrm{O}}$ 147, 201-222.

RUIZ MOYA (1994): «Observaciones sobre AE. Situación actual y perspectivas en España y Andalucía» en Actas del VII Coloquio de Geografía rural. Córdoba, 728-297.

SERVER IZQUIERDO, R.J., MATEOS RONCOS, A., LAJARA DE CAMILLERI, N. (2009): Cuestiones referentes al sector citrícola más relevantes para la definición de la política de seguros agrarios: situación actual y tendencias a corto y medio plazo. Centro de investigación en gestión de empresas. Universidad Politécnica de Valencia.

SPREEN THOMAS, H. (2010): Proyecciones de la producción y consumo mundial de los cítricos para el 2010. AO.org/docrep/fao. Simposio sobre cítricos. 
